\title{
El debido proceso para sancionar faltas administrativas disciplinarias leves en la Policía Nacional del Ecuador
}

\section{Due process to sanction minor administrative disciplinary offenses in the Ecuadorian National Police}

\author{
Richard Fernando Cuenca-Correa \\ richard.cuenca@psg.ucacue.edu.ec \\ Universidad Católica de Cuenca, Cuenca \\ Ecuador \\ https://orcid.org/0000-0003-2986-7364 \\ Cecilia Ivonne Narváez-Zurita \\ inarvaez@ucacue.edu.ec \\ Universidad Católica de Cuenca, Cuenca \\ Ecuador \\ https://orcid.org/0000-0002-7437-9880 \\ Juan Carlos Erazo-Álvarez \\ jcerazo@ucacue.edu.ec \\ Universidad Católica de Cuenca, Cuenca \\ Ecuador \\ https://orcid.org/0000-0001-6480-2270 \\ Diego Fernando Trelles-Vicuña \\ dtrelles@ucacue.edu.ec \\ Universidad Católica de Cuenca, Cuenca \\ Ecuador \\ https://orcid.org/0000-0002-8466-7165
}

Recibido: 12 de abril de 2020 Revisado: 14 de mayo de 2020 Aprobado: 26 de mayo de 2020

Publicado: 14 de junio de 2020 


\section{RESUMEN}

En esta investigación se realizó un estudio del debido proceso, su origen formal en los instrumentos internacionales de derechos humanos y su regulación en el Ecuador, enfocando el análisis en las garantías de la oralidad, el derecho a ser oído y las connotaciones del debido proceso en el ámbito administrativo disciplinario policial para determinar si se respeta el debido proceso en la sustanciación de faltas administrativas disciplinarias leves. En la investigación se utilizó un método transversal, con carácter descriptivo, aplicando un enfoque mixto combinando la técnica cualitativa y cuantitativa; además de revisar fuentes bibliográficas. La solución sería que la Asamblea Nacional del Ecuador tramite la reforma del artículo 126 del Código Orgánico de las Entidades de Seguridad Ciudadana y Orden Público, incluyendo en este procedimiento las garantías de la oralidad y el derecho a ser oído, para que de esta manera, se garantice el debido proceso desde su esfera formal.

Descriptores: Derecho constitucional; procedimiento legal; derecho a la justicia; solución de conflictos. (Palabras tomadas del Tesauro UNESCO).

\section{ABSTRAC}

In this research, a study of due process, its formal origin in international human rights instruments and its regulation in Ecuador, was conducted, focusing the analysis on the guarantees of orality, the right to be heard and the connotations of due process in the police disciplinary administrative area to determine if due process is respected in the substantiation of minor administrative disciplinary offenses. In the research, a descriptive transversal method was used, applying a mixed approach combining the qualitative and quantitative technique; in addition to reviewing bibliographic sources. The solution would be for the National Assembly of Ecuador to process the reform of article 126 of the Organic Code of the Citizen Security and Public Order Entities, including in this procedure the guarantees of orality and the right to be heard, so that, in this way, due process is guaranteed from its formal sphere.

Descriptors: Constitutional law; legal procedure; right to justice, conflict resolution. (Words taken from the UNESCO Thesaurus)

\section{INTRODUCCIÓN}

Los derechos establecidos en la Constitución de la República del Ecuador y en los instrumentos internacionales de derechos humanos son de directa e inmediata aplicación por parte de las autoridades jurisdiccionales o administrativas, dentro de los cuales se encuentra el debido proceso, su objetivo tiene doble función, por una parte es un derecho 
de los justiciables y por otra impone una obligación de garantía o cumplimiento a la autoridad, evitando una actuación arbitraria; en consecuencia, en todo proceso o actuación del Estado en la que se involucren derechos de los ciudadanos se debe garantizar el debido proceso en su integralidad.

Este derecho tiene su origen formal en los instrumentos internacionales de derechos humanos y que en lo posterior fue incorporado en el ordenamiento jurídico interno como consecuencia de la suscripción y ratificación de ellos, por parte del Ecuador, a partir de lo cual el poder legislativo en ejercicio de su facultad ha emitido leyes sancionatorias y sin incorporar en todas ellas las garantías del debido proceso previstas a nivel convencional y constitucional.

Al debido proceso lo conforman varias garantías, dentro de las cuales se centrará el estudio y análisis en la oralidad y el derecho a ser oído, ya que en la actualidad estas garantías han alcanzado tal relevancia y protagonismo, las mismas que se articulan con otras garantías y permiten un efectivo ejercicio del derecho a la defensa; enfatizando que estas garantías a nivel jurisdiccional se han materializado dentro del quehacer jurídico y en la aplicación del derecho en Ecuador.

Ante lo expuesto, se debe precisar que el procedimiento legal para sancionar las faltas administrativas disciplinarias leves en la Policía Nacional, violenta este derecho, pues no garantiza la oralidad y el derecho a ser oído; lo cual ocasiona una grave afectación a los derechos de los servidores policiales, que como consecuencia de procesos y sanciones administrativas injustas se ven impedidos de acceder a cursos de profesionalización, ascensos, entre otros; e incluso han sido separados de la Institución Policial.

En este contexto, es indudable que las garantías del debido proceso deben respetarse en materia administrativa; en virtud de los antecedentes mencionados el problema de la presente investigación radica en determinar: ¿Cómo afecta la vulneración del debido proceso en las sanciones por faltas administrativas disciplinarias leves a los servidores de la Policía Nacional del Ecuador? Por consiguiente, el objetivo de la presente investigación consiste en proponer la reforma del artículo 126 del Código Orgánico de las Entidades de Seguridad Ciudadana y Orden Público, referente al procedimiento para 
sancionar las faltas administrativas disciplinarias leves con la finalidad que se garantice la oralidad y el derecho a ser oído como parte integrante del debido proceso, mediante el estudio de este derecho a nivel convencional, constitucional y legal.

\section{Referencial teórico}

\section{El derecho constitucional al debido proceso}

El debido proceso constituye el respeto irrestricto de un sinnúmero de garantías -en especial en el ámbito procesal- que se encuentran preestablecidas o tienen su fundamento normativo en diversos cuerpos legales. En el Ecuador para hablar del debido proceso corresponde estudiar tratados internacionales de derechos humanos, la Constitución, así como normas infraconstitucionales que permiten entender el objeto y alcance de este derecho. Dado que al debido proceso lo conforman varias garantías se centrará el estudio y análisis en la oralidad y el derecho a ser oído, ya que esto permitirá alcanzar el objetivo planteado en este artículo.

Al respecto, la (Organización de Naciones Unidas, 1966) a través del artículo 14 del Pacto Internacional de Derechos Civiles y Políticos dispone que en la sustanciación de un proceso penal o civil, al acusado le asiste el derecho a ser oído como una garantía del debido proceso; por su parte, la (Organización de Estados Americanos, 1969) en el artículo 8 de la Convención Americana sobre Derechos Humanos, bajo la etiqueta de garantías judiciales reconoce que al sustanciar un proceso la autoridad competente deberá escuchar a la persona imputada dentro de un plazo razonable.

En materia de derechos humanos, los instrumentos internacionales ratificados por el Ecuador gozan o se encuentran al mismo nivel jerárquico que la Constitución de la República e incluso se sobreponen a ella en el caso de proteger con mayor amplitud los derechos; por consiguiente, toda autoridad pública o jurisdiccional están en la obligación de garantizar de oficio el respeto de los derechos previstos en estos instrumentos internacionales quedando proscrita la posibilidad de aducir falta de norma para su inaplicación (Asamblea Nacional Constituyente, 2008). Como se aprecia, la misma Constitución se subordina a los instrumentos internacionales de derechos humanos, 
cuando aquellos contengan derechos más favorables para los ciudadanos y por otra parte, establece que los derechos son exigibles, inclusive en el caso que no se encuentren regulados en normas infraconstitucionales.

En este contexto, la (Asamblea Nacional Constituyente, 2008) en torno al debido proceso dispuso: a) la emisión de una regla e imposición de una obligación a la autoridad administrativa o jurisdiccional de hacer efectivas las disposiciones legales y los derechos de las partes; b) que dentro del derecho a la defensa en el momento adecuado se escuche al procesado; c) la facultad de formular sus pretensiones de manera oral o escrita. Lo descrito hace referencia a las garantías de la oralidad y el derecho a ser oído que deben ser garantizadas por la autoridad competente en la sustanciación de todo proceso.

Continuando con las normas constitucionales, el artículo 169 enuncia los principios por los cuales se regirán las normas procesales o adjetivas en todas las materias y son: simplificación, uniformidad, eficacia, inmediación, celeridad y economía procesal, y culmina emitiendo una regla disponiendo que deberán hacerse efectivas las garantías del debido proceso (Asamblea Nacional Constituyente, 2008), de lo cual se deduce que sus garantías deben ser observadas desde el inicio hasta la finalización de un proceso y en todas las materias.

Los términos derecho o garantía, a veces son utilizados como sinónimos, sin embargo, existe una diferencia conceptual que debe ser tomada en cuenta. La garantía protege y permite la efectivización de un derecho, es la herramienta por medio de la cual las personas pueden salvaguardar sus derechos frente a las autoridades y a las demás personas (Calvinho, 2013). Un derecho por sí solo no goza de eficacia, en la práctica jurídica necesita la activación de una o más garantías para materializarse; un derecho es una facultad, una atribución, algo que le pertenece a la persona, cuya tutela le es encomendada a las garantías.

Al ser el debido proceso un derecho, es importante tomar en cuenta lo que implica. "Los derechos son valores intrínsecos de la persona, no meras declaraciones o creaciones arbitrarias, sujetas al vaivén del Poder (...)" (Burneo, 2010, p.65). Es una definición corta 
y a su vez con amplio contenido, de donde sobresalen dos circunstancias: I) Que los derechos son inseparables de la persona, le son inherentes a su condición de ser humano. II) La autoridad pública o jurisdiccional no goza de discrecionalidad para su cumplimiento, no está a su arbitrio, por el contrario está obligada a garantizarlos.

El mismo autor en cuanto al derecho a debido proceso emite una amplia definición. Este derecho es de carácter sustantivo y procesal, provisto de un conjunto de derechos, establecidos en la Constitución, su objetivo es cuidar la libertad y que las personas puedan defender sus derechos en el campo jurisdiccional o administrativo, y constituye una obligación del Estado garantizar su aplicación, procurar un proceso ágil, diáfano e imparcial; y dada su jerarquía normativa se sobrepone a cualquier norma infraconstitucional (Ibídem).

Esta definición contiene ciertas imprecisiones e incluso contradicciones: 1) no se podría coincidir que el debido proceso sea un conjunto de derechos, pues se conoce que a este derecho lo componen o articulan un conjunto de garantías. 2) El aseverar que el debido proceso tiene rango constitucional es adecuado; sin embargo, omite mencionar la categoría convencional que ostenta. 3) Al incluir el término -procura- equivale a otorgarle discrecionalidad a la autoridad, deja a su arbitrio el cumplimiento o no del debido proceso. 4) Se centra en el proceso y deja al margen el fin mismo del debido proceso que está en la decisión o sentencia ya que en ella se refleja la materialización de este derecho.

En el orden jurisprudencial la Corte Constitucional ecuatoriana se ha pronunciado de forma reiterativa sobre este derecho. El debido proceso no constituye adoptar un mero procedimiento metódico, ordenado y regulado, donde se destaquen más los aspectos formales que el contenido mismo o lo sustancial; lo que importa es garantizar el ejercicio pleno de los derechos esenciales y que la decisión sea el resultado de la aplicación de los principios constitucionales (Sentencia No. 001-12-SEP-CC, 2012). Por otra parte, en la (Sentencia No. 203-17-SEP-CC, 2017) se expone: que el debido proceso es un conjunto de garantías aplicables en la sustanciación de un proceso judicial o administrativo, mediante las cuales se aspira proteger los derechos constitucionales y 
convencionales, e impide un accionar discrecional de la autoridad pública o jurisdiccional; en este punto se puede hablar de la materialización de las garantías del debido proceso. Por cuanto se trata de casos concretos resueltos por la Corte Constitucional, considerando que sus decisiones son vinculantes para toda autoridad judicial 0 administrativa. Sobresale la importancia que le atribuye al debido proceso que no se trata de regirse a un simple procedimiento reglado, a una mera formalidad, sino un respeto efectivo de los derechos de las personas, a ellos se encuentra subordinada la autoridad quien deberá emitir una sentencia justa. Como crítica no debería utilizar el término aspira ya que le otorga un carácter discrecional a las garantías del debido proceso, lo adecuado sería utilizar el término obliga o exige, debido al carácter imperativo que es propio del debido proceso.

\section{El debido proceso en el ámbito administrativo}

Los instrumentos internacionales y la Constitución de la República del Ecuador no discriminan sobre el cumplimiento del debido proceso en ciertas materias, por el contrario, este derecho obliga a toda actuación del Estado donde se involucren derechos de los ciudadanos; y por otra parte, es obvio que los derechos de los administrados merecen ser tutelados por la relación de poder que ostenta la administración pública y mucho más si se toma en cuenta que el Estado es el mayor vulnerador de derechos.

En cuanto a esta temática, la administración pública para otorgarle validez a sus decisiones debe cumplir ciertos requisitos: precautelar los derechos de los administrados; garantizar el acceso y participación de quienes pudiesen ver afectados sus derechos, previo a la decisión administrativa; autoproteger mediante el proceso administrativo los derechos de la misma administración; y, tutelar los derechos de los administrados (Hernández, 2017). El expresado criterio, permite inferir que una actuación o decisión de la administración sin haberse observado los derechos de los administrados carece de eficacia jurídica. 
Por otra parte, (López, Narváez, Vázquez , \& Erazo, 2019) y (Cañarte , Erazo , Vázquez, \& Narváez , 2019) sobre el debido proceso en el ámbito administrativo afirman que no se garantiza el derecho a ser juzgado por un juez natural en procedimientos administrativos; $y$, es una herramienta jurídica que impide la vulneración de derechos en una actuación estatal. Es evidente que en materia administrativa no se garantiza la imparcialidad del juzgador ya que siempre va a ser un funcionario de la misma institución pública quien cumpla esta función.

En el Ecuador se cuenta con un cuerpo normativo que regula la materia administrativa y no prevé una definición o delimitación de las garantías del debido proceso, en su lugar incorpora ciertos principios por los cuales se regirá la administración pública. Toda actuación de la administración estará sujeta a normas constitucionales, instrumentos internacionales, leyes, principios y jurisprudencia aplicable; a toda entidad pública le está prohibido interpretaciones o actuaciones arbitrarias, por lo que sus actos serán consecuencia de la aplicación de los principios de juridicidad e igualdad (Asamblea Nacional del Ecuador, 2017). Si bien es cierto, no existe regulación expresa sobre el derecho al debido proceso; sin embargo, al referir que todo acto de la administración debe ceñirse a la Constitución de la República, realiza una regulación implícita.

A partir del análisis realizado, corresponde revisar la ley específica que regula los procesos administrativos en la Policía Nacional del Ecuador, para imponer una sanción es obligatoria adoptar el procedimiento administrativo cumpliendo con el debido proceso previsto en la Constitución de la República (Asamblea Nacional del Ecuador, 2017). Es evidente que el legislador ha decidido direccionar los procesos administrativos disciplinarios policiales al cumplimiento de las garantías del debido proceso establecidas en la Constitución de la República, omitiendo considerar las garantías vinculantes previstas en el bloque de convencionalidad con lo cual se demuestra que se menoscaba la relevancia de este derecho desde su dimensión formal; no obstante, en el caso específico de las faltas leves, se vulnera el debido proceso establecido en la Constitución. Al respecto, el debido proceso en materia administrativa constituye un conjunto de garantías inmutables en el trámite de procesos judiciales y administrativos con la finalidad 
de resguardar los derechos constitucionales e impedir un desempeño facultativo de la autoridad jurisdiccional o pública.

Este derecho permite que las personas consigan una decisión fundada y justa, bajo el amparo de la Constitución y la ley, en la sustanciación de un proceso de cualquier índole. (Ruiz, Aguirre, \& Ávila, 2016). De lo expuesto por estos autores se destaca lo siguiente: i) las garantías del debido proceso son obligatorias en el ámbito jurisdiccional y administrativo; ii) evita una actuación discrecional de las autoridades; iii) son vinculantes en el desarrollo del proceso y se materializa con una sentencia justa; iv) los autores no hacen referencia a la jerarquía convencional que tiene este derecho.

Mientras tanto, la Corte Interamericana de Derechos Humanos en -adelante Corte IDHsobre el debido proceso en materia administrativa ha generado amplia jurisprudencia; disponiendo que las garantías judiciales no se circunscriban de forma exclusiva al ámbito judicial, ya que se garantizará el debido proceso legal en todo proceso o actuación del Estado, sea administrativo sancionatorio, disciplinario o jurisdiccional (Sentencia Flor Freire vs Ecuador. Excepción Preliminar, Fondo, Reparaciones y Costas, 2016). En otras palabras, se infiere la dualidad de objeto del debido proceso que protege los derechos de las personas e impone una obligación de cumplimiento a la autoridad; como crítica se expone el desacuerdo con la expresión: -se garantizará el debido proceso legal-, ya que el procedimiento legal puede vulnerar derechos constitucionales, como es el caso materia de este estudio.

El debido proceso constituye un auténtico valor protegido por la ley, es un medio para alcanzar la justicia, su cumplimiento vincula a un proceso disciplinario; los Estados no pueden abstraerse de cumplir el artículo 8 de la Convención en sanciones disciplinarias, ya que ello significaría dejar a su albedrío el respeto del debido proceso en materia administrativa disciplinaria (Corte Interamericana de Derechos Humanos, 2017). La situación descrita es muy relevante, pues, de generarse un incumplimiento del debido proceso en sanciones disciplinarias en contra de servidores policiales, bien podría acarrear responsabilidad internacional del Estado, en el supuesto que el caso llegase a conocimiento de la Corte IDH. 
Tanto la Corte IDH como la Corte Constitucional ecuatoriana han plasmado en su jurisprudencia que en procesos administrativos, al igual que en el ámbito jurisdiccional, se deben respetar las garantías del debido proceso, más, han descuidado desarrollar criterios, parámetros o garantías mínimas que sirvan de guía a las autoridades públicas que cumplen el rol de jueces en el ámbito administrativo; como si existe en otros países como Colombia.

La Corte Constitucional colombiana mediante (Sentencia C-980/10, 2010) estableció varias garantías como parte de este derecho: ser oído, notificación oportuna, participación activa, presunción de inocencia, ejercer contradicción, solicitar pruebas, entre otras. Enfatizando que esta Corporación ha mantenido esta línea jurisprudencial a través del tiempo, prueba de ello estas mismas garantías fueron enunciadas en la (Sentencia T-001/19, 2019).

La Corte Constitucional de Colombia acredita un alto prestigio a nivel latinoamericano, por lo sustancial de sus decisiones y por su desarrollo jurisprudencial, en el caso concreto se aprecia que establece un cúmulo de garantías que permiten precautelar de manera efectiva los derechos de los administrados e imponer una obligación a la autoridad pública, evitando una actuación arbitraria, y en consecuencia se configura la dualidad funcional del debido proceso derecho-obligación.

\section{La oralidad y el derecho a ser oído como garantías transversales del debido proceso}

La garantía de la oralidad es fundamental dentro del debido proceso ya que es interdependiente con las demás garantías, por consiguiente, su inobservancia implica per se la vulneración del debido proceso, con las consecuencias lógicas que ello implica. Es importante referir que esta garantía a nivel convencional ha sido desarrollada a través de la jurisprudencia de la Corte IDH, y al formar parte del bloque de convencionalidad se vuelve vinculante para las autoridades jurisdiccionales y administrativas del Ecuador.

En este orden de ideas, la Corte IDH expuso que: La oralidad forma parte de las debidas garantías previstas en el artículo 8 de la Convención, lo cual debe ser garantizado por los 
Estados a sus ciudadanos en la sustanciación de ciertos procesos (Sentencia Apitz Barbera y otros Corte Primera de lo Contencioso Administrativo vs. Venezuela, 2008), en esta sentencia se aprecia cierta contradicción de la Corte IDH, ya que por una parte incorpora a la oralidad como una garantía del debido proceso y expresa que es aplicable en ciertos procesos; cuando en su jurisprudencia ha sido reiterativa en exponer que las garantías del debido proceso deben observarse en toda actuación del Estado en la que estén involucrados derechos de las personas.

A nivel del ordenamiento jurídico ecuatoriano la oralidad adquiere protagonismo y se garantiza en su dimensión formal con la entrada en vigencia de la actual Constitución de la República, donde expone: "La sustanciación de los procesos en todas las materias, instancias, etapas y diligencias se llevará a cabo mediante el sistema oral, de acuerdo con los principios de concentración, contradicción y dispositivo" (Asamblea Nacional Constituyente, 2008, art.168). La Constitución de la República en el numeral 6 de la norma aludida, de forma taxativa impone una regla donde la garantía de la oralidad es vinculante en todos los procesos, desde su inicio hasta su culminación.

Por su parte, la Corte Constitucional ecuatoriana se ha pronunciado sobre la importancia de esta garantía, considerando a la oralidad como principio transversal en materia penal; esta garantía permite la materialización de otros principios procesales en la sustanciación de los procesos legales, en especial en cuanto a su agilidad y la participación directa y activa de los sujetos procesales (Sentencia No. 006-16-SCN-CC, 2016). Es evidente la importancia que la Corte le atribuye a la oralidad al aseverar que es el principio rector dentro de un proceso, es una herramienta para alcanzar otros principios procesales dentro de la administración de justicia, como es la celeridad y participación activa de los involucrados en el proceso; sin oralidad no existe debido proceso.

Por su parte, (Guzmán, 2019) expresa que la aplicación de la oralidad en un proceso legal permite garantizar la tutela judicial efectiva del justiciable. Vincular la garantía de la oralidad con el cumplimiento del derecho constitucional a la tutela judicial efectiva, no es otra cosa que aseverar lo significativo de la oralidad para defender de forma acertada los derechos de las personas. En la ley específica que regula los procesos administrativos 
disciplinarios en la Policía Nacional, en cuanto a esta garantía el artículo 54 del Código Orgánico de las Entidades de Seguridad Ciudadana y Orden Público, dispone que el procedimiento será oral garantizando el debido proceso (Asamblea Nacional del Ecuador, 2017). Este precepto normativo contiene una regla y con ello se estaría garantizando en su dimensión formal la oralidad en estos procedimientos; sin embargo, más adelante se analizará que el legislador comete una contradicción ya que al regular el procedimiento específico para las faltas leves en la Policía Nacional establece un procedimiento inquisitivo, por lo que omite la oralidad.

El proceso oral es acorde a los requerimientos contemporáneos de la justicia, ya que permite un proceso económico, simple y ágil, garantizando el fin último del derecho que es la justicia (Quiroz \& Quiroz, 2016). La oralidad es el mecanismo central del proceso, donde la autoridad escucha los alegatos de las partes y permite la conjugación de los principios constitucionales y garantías procesales (Restrepo \& Botero, 2018). La oralidad otorga al sumariado la posibilidad de ser escuchado por la autoridad que emitirá la resolución, beneficia la contradicción e inmediación (Hernández, 2017).

Concluyendo dentro de este temática se puede asegurar que es imperativo la aplicación de la oralidad en los procesos administrativos disciplinarios en la Policía Nacional, ya que sólo así se puede garantizar los derechos de los servidores policiales, generándose resoluciones justas; y ello sin duda constituirá un cambio total del paradigma enquistado a lo largo de la historia en esta noble institución, donde se transite de -las decisiones de hecho por decisiones en derecho; que la voluntad del superior jerárquico se subordine a la norma-.

En lo referente a la garantía del derecho a ser oído es pertinente revisar la jurisprudencia emitida por la Corte IDH. Este derecho protegido en el artículo 8.1 de la Convención le permite a la persona de quien sus derechos $u$ obligaciones se encuentran en conflicto, acceder ante la autoridad y expresar sus argumentos de manera oral (Sentencia Barbani Duarte y Otros Vs. Uruguay. Fondo Reparaciones y Costas, 2011). En este contexto, en un caso administrativo disciplinario militar la Corte IDH refirió: el derecho a ser oído involucra dos ámbitos: 1. formal y procesal, acceso ante la autoridad que decidirá sobre 
sus derechos presentando alegatos y prueba; 2 . de protección material, la decisión estatal debe satisfacer la justicia (Sentencia Rosadio Villavicencio Vs. Perú. Excepciones Preliminares, Fondo, Reparaciones y Costas, 2019).

En el ámbito de la jurisprudencia nacional, el derecho a ser oído debe ser garantizado durante todo el proceso, con la exposición de las pretensiones, elementos probatorios y ejerciendo contradicción (Sentencia No. 018-09-SEP-CC, 2009). Es notorio que esta garantía es importante porque permite la materialización de otros principios procesales como son: la inmediación, publicidad, contradicción, entre otros; y todos ellos de jerarquía constitucional. En este orden de ideas, este derecho también ha sido abordado a nivel doctrinario; para que un sistema de justicia cumpla con el debido proceso según la Convención Americana de Derechos Humanos, dentro de los elementos más importantes debe garantizar que la persona sea oída mediante la celebración de una audiencia (Villadiego, 2010).

Por último, corresponde analizar la disposición normativa que regula el procedimiento para sancionar las faltas administrativas disciplinarias leves en la Policía Nacional del Ecuador, con la finalidad de cerciorarse si cumple con el debido proceso en el ámbito formal, en especial las garantías ya analizadas; al respecto dispone:

a) Trámite de la información o denuncia en faltas administrativas disciplinarias leves.- Cuando se trate del cometimiento de faltas administrativas disciplinarias leves se observará el siguiente procedimiento: El servidor o servidora policial sobre el cual exista presunción del cometimiento de una infracción dispondrá del término de dos días contados a partir de la notificación de los hechos que se le imputan, para presentar las pruebas de descargo. El superior jerárquico emitirá, en el término de tres días posteriores al término que tiene el servidor o servidora para presentar su prueba de descargo, la resolución que corresponda. La resolución emitida por el superior jerárquico de la institución deberá estar debidamente motivada, de conformidad con la Constitución de la República y este Código. Esta resolución será remitida al órgano competente del ministerio rector de la seguridad ciudadana, protección interna y orden público para su respectivo, registró en la 
hoja de vida de la o el servidor policial. (Asamblea Nacional del Ecuador, 2017, art.126)

Es fácil advertir que este procedimiento legal no garantiza la oralidad y el derecho a ser oído, por tanto, vulnera el derecho al debido proceso establecido a nivel convencional y constitucional; de ahí que los derechos de más de 50.000 servidores policiales son vulnerados en su dimensión formal y material, e inclusive no se prevé la realización de una audiencia para sancionar este tipo de faltas, generándose un retroceso a un proceso inquisitivo.

\section{MÉTODO}

La presente investigación fue transversal con un carácter descriptivo, donde se analizó el derecho al debido proceso en el procedimiento para sancionar las faltas administrativas disciplinarias leves en la Policía Nacional del Ecuador, centrando el estudio en la oralidad y el derecho a ser oído como garantías transversales de este derecho. Las fuentes utilizadas para la obtención de la información fueron: tratados y convenios internacionales en materia de derechos humanos, Constitución de la República del Ecuador, leyes orgánicas, jurisprudencia nacional e internacional, artículos científicos indexados en Scielo, Lexis Finder, revistas jurídicas, sitios web, repositorios, entre otros.

Se aplicó un enfoque mixto, destacando la técnica cualitativa donde predominó el análisis teórico mediante la revisión bibliográfica relacionada con el derecho al debido proceso direccionado al ámbito administrativo con la finalidad de abordar la temática que es objeto del presente estudio. Por otra parte, el enfoque cuantitativo se realizó a través de estadística inferencial, generando datos por intermedio de una encuesta dirigida a abogados en libre ejercicio de la profesión, servidores policiales con título de abogados y que cumplen funciones en los departamentos jurídicos y de Asuntos Internos, quienes se encargan de sustanciar y resolver procesos administrativos disciplinarios; y, a servidores policiales en general.

En la presente investigación se utilizaron los siguientes métodos: el histórico - lógico partiendo desde el origen formal del derecho al debido proceso a nivel latinoamericano, 
la incorporación de este derecho a nivel constitucional, y un análisis cronológico de la jurisprudencia nacional e internacional; además, se aplicó el método analítico - sintético que permitió establecer que el derecho al debido proceso está conformado por varias garantías entre las que sobresalen la oralidad y el derecho a ser oído, lo cual otorgó fundamento para alcanzar el objetivo propuesto; $y$, el método inductivo - deductivo permitió establecer desde la generalidad del derecho al debido proceso, demostrar que el procedimiento para sancionar las faltas administrativas disciplinarias en la Policía Nacional del Ecuador previsto en el artículo 126 del Código Orgánico de las Entidades de Seguridad Ciudadana y Orden Público no garantiza el debido proceso.

La población encuestada fue escogida mediante un muestreo por conveniencia aplicando una técnica no aleatoria y no probabilística, la misma que estuvo conformada por 24 abogados, entre policías en servicio activo y abogados en libre ejercicio de la profesión, y 11 servidores policiales; empleando criterios de conocimiento de procesos administrativos disciplinarios y servidores policiales que se han encontrado involucrados en dichos procesos.

\section{RESULTADOS}

La encuesta realizada generó valiosa información que necesita ser analizada con la finalidad de otorgarle un fundamento constitucional a la presente investigación, relacionada al derecho al debido proceso en el ámbito administrativo policial, se contó con dos unidades de análisis, con una encuesta dirigida tanto a abogados en libre ejercicio y Policías en servicio activo con título de abogado, y otra encuesta dirigida a servidores policiales en general; al constituir un trabajo académico se tomó en cuenta que los encuestados tengan conocimiento de los procedimientos administrativos disciplinarios policiales y/o se hayan encontrado involucrados en uno de ellos. La primera encuesta estuvo conformada por 13 preguntas con opciones concretas de respuesta y la segunda con 9 preguntas de estructura idéntica; de los resultados obtenidos se destaca lo siguiente: 
Los encuestados profesionales del derecho aseguran en un $87,5 \%$ que las garantías del debido proceso son aplicables en los procedimientos administrativos disciplinarios en la Policía Nacional del Ecuador, en la sustanciación de todo tipo de faltas, mientras que, el $12,5 \%$ consideran que el derecho al debido proceso sólo se lo debe aplicar al sustanciar faltas graves; lo cual denota que aún existen abogados -en un porcentaje mínimo- que consideran que este derecho debe ser respetado en ciertos procesos, cuando lo correcto es que se lo garantice en toda actuación del Estado en donde estén involucrados derechos de las personas.

Así mismo, al consultarles si un servidor policial involucrado en un proceso administrativo disciplinario podría renunciar a su derecho al debido proceso, el 95,8\% expone que no lo pueden hacer y el 4,2\% que representa a una persona de las 24 encuestadas, menciona que en ocasiones sí procede renunciar a este derecho; por consiguiente, es necesario tomar en cuenta que los derechos humanos son inalienables, irrenunciables, indivisibles entre otras características, ya que le pertenecen de forma intrínseca a la persona.

Un dato relevante constituye que el 100\% considera que respetar ciertas garantías del debido proceso y transgredir otras, vulnera el debido proceso; y ello permite inferir que este derecho siempre debe ser respetado en su integralidad. Coinciden también el 100\% de los consultados que la oralidad y el derecho a ser oído son garantías del debido proceso; por lo tanto, su respeto constituye una obligación de toda autoridad pública al momento de resolver un proceso administrativo.

En este contexto, se les consultó si un servidor policial podría ejercer de manera efectiva su derecho a la defensa al no existir oralidad ni garantizarle su derecho a ser oído, a lo que el $62,5 \%$ manifestaron que no, el $20,8 \%$ que sí y el $16,7 \%$ expusieron que se pueden defender parcialmente; como se aprecia, existen tres matices que al analizarlos de manera exhaustiva permite concluir que el $79,2 \%$ aseguran que se irrespeta el derecho a la defensa cuando no se garantiza la oralidad y el derecho a ser oído de un servidor policial inculpado por una falta administrativa disciplinaria leve (ver figura 1). 


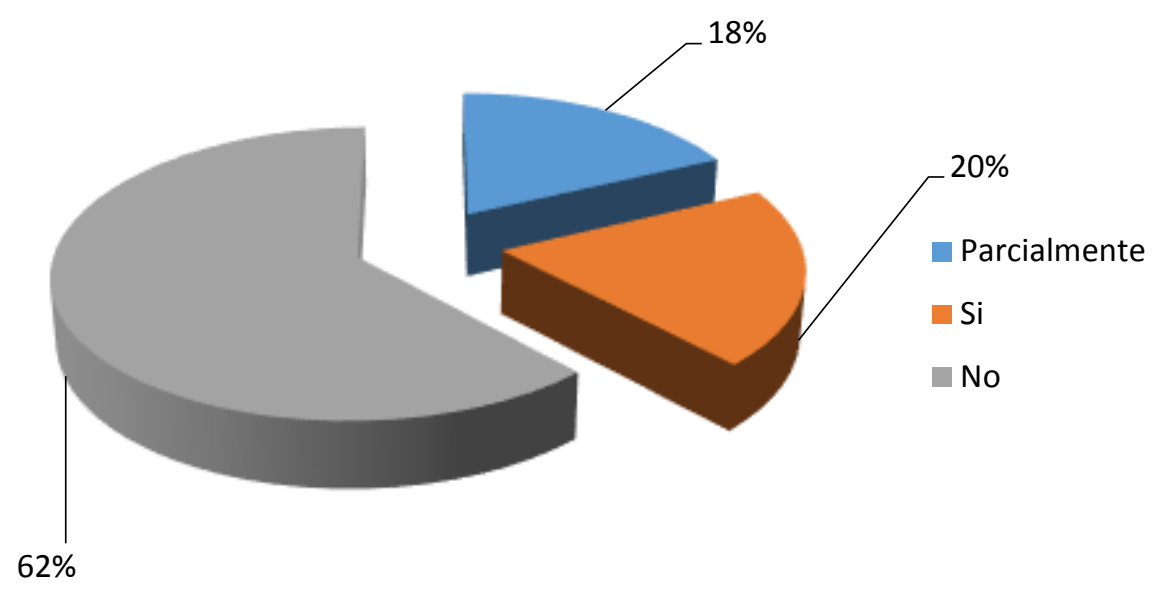

Figura 1. Sin oralidad y derecho a ser oído no hay derecho a la defensa

En otra interrogante se planteó cuál sería la solución para que se incorpore la oralidad y el derecho a ser oído en el procedimiento para sancionar las faltas leves en la Policía Nacional del Ecuador, a lo que el $62 \%$ refirió que corresponde plantear una reforma legal por intermedio de la Asamblea Nacional, el 6\% sostuvo que lo adecuado es presentar una acción de inconstitucionalidad ante la Corte Constitucional y el 33\% restante expuso que son viables cualquiera de las dos soluciones; enfatizando que el objetivo del presente trabajo es proponer una reforma legal y con eso coinciden la mayoría de los encuestados (ver figura 2). 


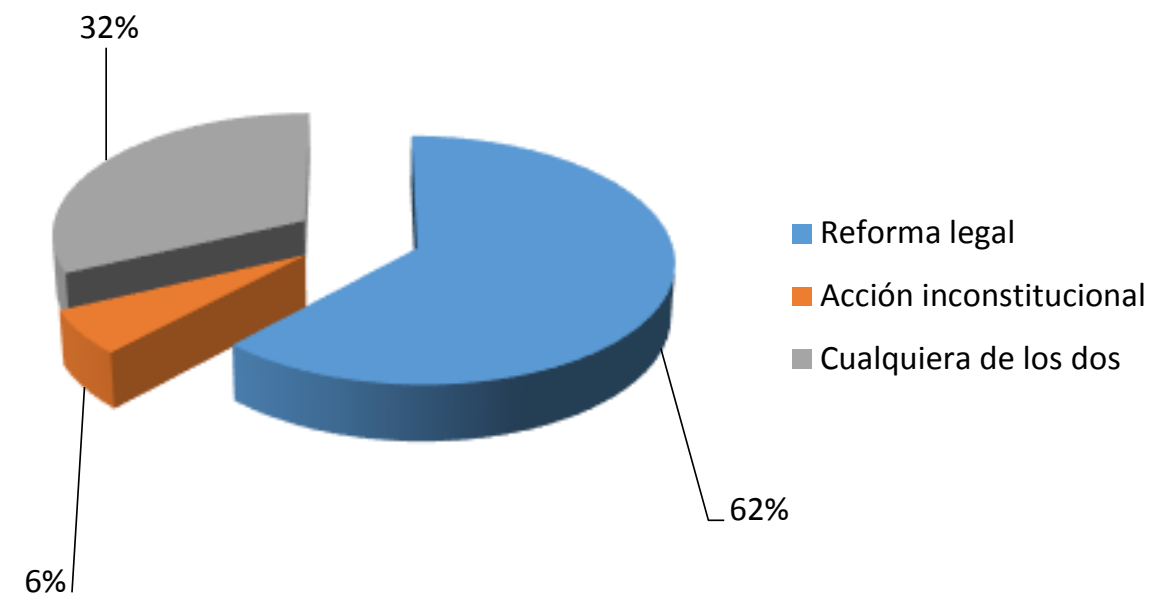

Figura 2. Incorporación de la oralidad y el derecho a ser oído

En lo referente a la segunda unidad de análisis, los servidores policiales manifiestan en un porcentaje del $73 \%$ que si se aplicaría un procedimiento oral y se permitiría ejercer su derecho a ser oído en un procedimiento administrativo por faltas leves, estarían en condiciones de ejercer de mejor manera su derecho a la defensa, y el $27 \%$ aseguró que es probable un mejor ejercicio de la defensa sobre los hechos que se le imputan, cuando se garantice un proceso oral y se escuche al inculpado; es evidente que estas garantías son transversales en el derecho a la defensa.

Como consecuencia de no garantizar la oralidad y el derecho a ser oído, el 90,9\% de la población consultada asegura que las decisiones o resoluciones adoptadas en estos procedimientos disciplinarios son injustas ya que vulneran sus derechos constitucionales, mientras que, el 9,1\% que corresponde a una persona de las 11 encuestadas refiere que las decisiones son justas (ver figura 3); de lo expuesto, es evidente que se vulnera el fin mismo del debido proceso que es obtener una decisión que cumpla con los principios constitucionales. 


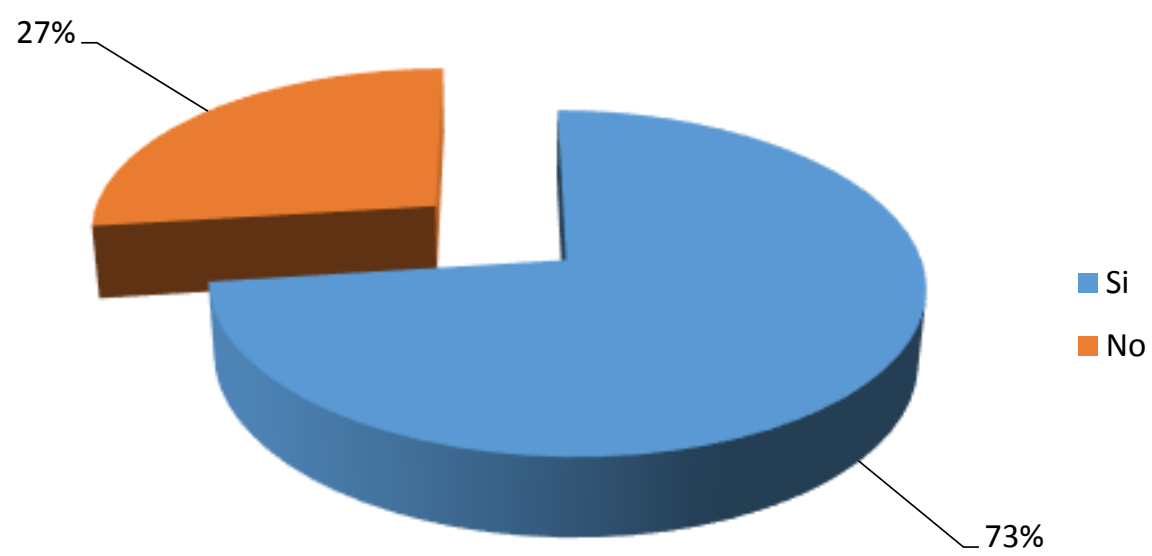

Figura 3. Resoluciones justas

\section{PROPUESTA}

Por la información obtenida, existe certeza sobre la imperiosa necesidad de reformar el artículo 126 del Código Orgánico de las Entidades de Seguridad Ciudadana y Orden Público, con la finalidad que en el procedimiento para sancionar las faltas leves en la Policía Nacional del Ecuador se garantice la oralidad y el derecho a ser oído, y de esta manera se evite la vulneración del derecho constitucional al debido proceso; de acuerdo con los parámetros que se detallan a continuación en la figura 4. 


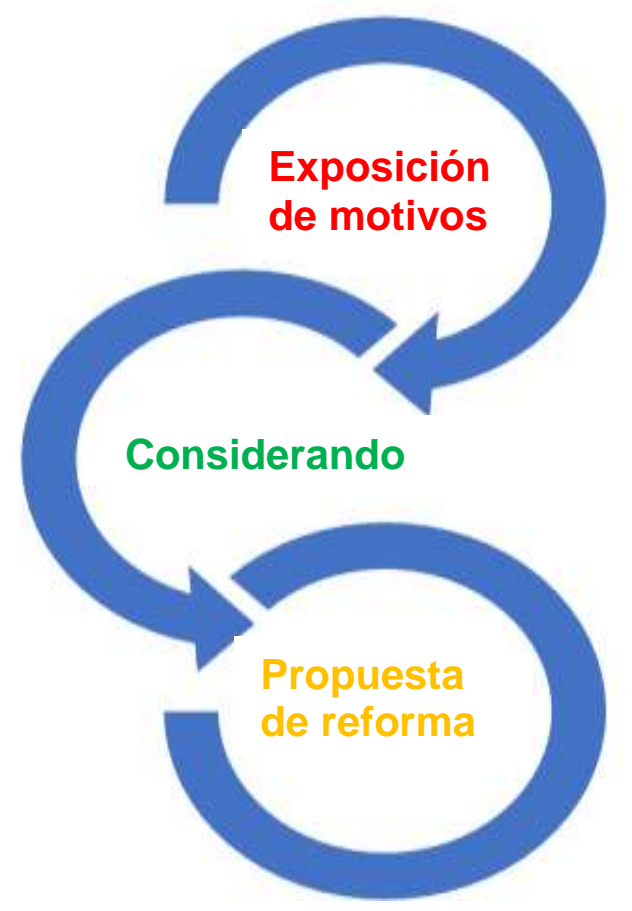

Figura 4. Esquema de Ley Reformatoria al Código Orgánico de las Entidades de Seguridad Ciudadana y Orden Público

\section{Ley Reformatoria al Código Orgánico de las Entidades de Seguridad Ciudadana y Orden Público \\ Exposición de motivos:}

El debido proceso es un derecho imprescindible que le permite a todos los ciudadanos defender sus derechos de toda actuación del Estado, así también, el debido proceso constituye una obligación para la autoridad jurisdiccional o administrativa de cumplir sus garantías, quedando proscrita una actuación arbitraria; en conclusión, este derecho permite alcanzar la justicia y tener decisiones o sentencias justas, donde se refleje la aplicación de todos los principios constitucionales.

Los servidores policiales que en la actualidad son más de 50.000 a nivel nacional, no pueden ni deben quedar al margen de la aplicación irrestricta del debido proceso en el ámbito administrativo disciplinario; ya que bajo la característica de universalidad de los 
derechos, no puede haber distinción para que este derecho deje de cumplirse en ciertos grupos sociales o para determinadas personas.

Los instrumentos internacionales de derechos humanos ratificados por el Ecuador y la Constitución de la República prevén un catálogo de derechos que protegen a todas las personas e incluso la jurisprudencia nacional e internacional dispone que el derecho al debido proceso debe cumplirse de manera imperativa en todo proceso, sea administrativo, judicial o de cualquier otra naturaleza; por lo tanto, toda sanción administrativa en la Policía Nacional debe estar precedida del respeto a las garantías del debido proceso.

La institución policial a lo largo de la historia dada su organización vertical jerarquizada, escudándose en un valor tan importante como la disciplina, ha permitido que los superiores jerárquicos vulneren este derecho en su dimensión formal y material; tomando en cuenta que antes de la entrada en vigencia del Código Orgánico de las Entidades de Seguridad Ciudadana y Orden Público (Diciembre de 2017), los procesos administrativos disciplinarios estaban regulados por un Reglamento de Disciplina (Redactado y aprobado por el mando institucional) que permitía a un superior jerárquico imponer una sanción de forma directa, sin otorgarle al servidor policial inculpado la más mínima posibilidad de defenderse y por consiguiente sin respetar el debido proceso.

Es irónico pensar que la institución encargada de velar y proteger el libre ejercicio de los derechos de los ciudadanos, por el contrario, no garantice los derechos de sus integrantes; y las consecuencias han sido nefastas: servidores policiales que han visto truncada su carrera porque no han podido acceder a cursos de profesionalización, negativa de ascensos y lo más grave, pérdida de su trabajo. Todo ello, en un contexto social que sin duda afecta al núcleo familiar del servidor policial y en consecuencia a la sociedad en su conjunto, ya que incluso ex servidores policiales se vinculan a bandas delictivas, lo cual podría atribuirse al hecho de haberse quedado sin empleo.

Esta problemática se subsanó en su mayor parte luego de la entrada en vigencia del Código Orgánico de las Entidades de Seguridad Ciudadana y Orden Público, sin embargo, el legislador al momento de regular el procedimiento para sancionar las faltas 
leves, omitió garantizar la oralidad y el derecho a ser oído de un servidor policial siendo estas garantías transversales para ejercer el derecho a la defensa y de esta manera se efectivice el debido proceso; ante lo cual es imperiosa la necesidad de reformar el artículo 126 del referido cuerpo normativo para evitar que se sigan vulnerando los derechos de los servidores policiales.

\section{Considerando:}

Que el artículo 14 del Pacto Internacional de Derechos Civiles y Políticos dispone que en la sustanciación de un proceso penal o civil, al acusado le asiste el derecho a ser oído como una garantía del debido proceso.

Que el artículo 8 de la Convención Americana sobre Derechos Humanos, bajo la etiqueta de garantías judiciales reconoce que al sustanciar un proceso la autoridad competente deberá escuchar a la persona imputada dentro de un plazo razonable.

Que el artículo 11 numeral 3 de la Constitución de la República, dispone que los derechos previstos en la Constitución y en los instrumentos internacionales de derechos humanos deben ser aplicados de manera preferente por parte de toda autoridad pública 0 jurisdiccional, quedando proscrita la posibilidad de aducir falta de norma para su inaplicación.

Que el artículo 11 numeral 4 de la Constitución de la República, dispone que los derechos y garantías previstos en ella no pueden ser limitados por una norma infraconstitucional.

Que el artículo 11 numeral 9 de la Constitución de la República, dispone que el Estado por intermedio de sus funcionarios y de toda persona que ostente una función pública, tiene como fin último respetar y hacer respetar los derechos constitucionales.

Que el artículo 76 de la Constitución de la República, en torno al debido proceso prevé: a) una regla e impone una obligación a la autoridad administrativa o jurisdiccional de hacer efectivas las disposiciones legales y los derechos de las partes; $\mathbf{b})$ que dentro del derecho a la defensa en el momento adecuado se escuche al procesado; c) la facultad de formular sus pretensiones de manera oral o escrita. 
Que el artículo 169 de la Constitución de la República enuncia los principios por los cuales se regirán las normas procesales o adjetivas en todas las materias y son: simplificación, uniformidad, eficacia, inmediación, celeridad y economía procesal, y culmina emitiendo una disposición que deberán hacerse efectivas las garantías del debido proceso.

Que el artículo 168 numeral 6 de la Constitución de la República dispone: La sustanciación de los procesos en todas las materias, instancias, etapas y diligencias se llevará a cabo mediante el sistema oral, de acuerdo con los principios de concentración, contradicción y dispositivo.

Que el artículo 54 del Código Orgánico de las Entidades de Seguridad Ciudadana y Orden Público, dispone que el procedimiento será oral garantizando el debido proceso.

Que el artículo 118 del Código Orgánico de las Entidades de Seguridad Ciudadana y Orden Público, dispone que previo a imponer una sanción es obligatorio adoptar el procedimiento administrativo cumpliendo con el debido proceso previsto en la Constitución de la República, garantizando el derecho a la defensa.

En ejercicio de las facultades previstas en el artículo 120 numeral 6 de la Constitución de la República, la Asamblea Nacional expide la siguiente:

\section{Ley Orgánica Reformatoria al Código Orgánico de las Entidades de Seguridad Ciudadana y Orden Público}

Artículo único.- Sustitúyase el artículo 126 del Código Orgánico de las Entidades de Seguridad Ciudadana y Orden Público, por el siguiente texto:

Artículo 126.- El procedimiento para sustanciar las faltas administrativas disciplinarias leves, será el siguiente:

Auto inicial: El superior jerárquico que cuente con elementos de convicción sobre la existencia material de una falta administrativa disciplinaria leve, de acuerdo con este Código, cometida por un servidor policial a su cargo, dictará el auto inicial debidamente motivado, donde constarán los fundamentos de hecho y derecho. 
Notificación: Con el auto inicial notificará al servidor policial inculpado en persona o mediante memorando dejado en su lugar de trabajo; de forma excepcional la primera actuación se podrá notificar en el correo institucional del servidor policial.

Contestación: El servidor policial notificado dará contestación y presentará sus pruebas de descargo en el plazo de 5 días, para lo cual contará con libertad probatoria, siendo facultativo contar con el patrocinio de un profesional del derecho.

Audiencia: Luego del plazo que tiene el servidor policial para dar contestación sobre los hechos que se le imputan, el superior jerárquico convocará a audiencia pública dentro de los 5 días siguientes, donde se garantizará la oralidad y el derecho a ser oído del servidor policial inculpado.

Resolución: En la audiencia el superior jerárquico, de manera oral, dará a conocer su resolución al servidor policial inculpado, la misma que será notificada por escrito en el término de 3 días.

Dado y suscrito en la Sede de la Asamblea Nacional, ubicada en el Distrito Metropolitano de Quito, a los...... días del mes de...... del año dos mil veinte.

\section{DISCUSIÓN}

El debido proceso es un derecho que se encuentra regulado en instrumentos internacionales de derechos humanos, en la Constitución de la República y en normativa infraconstitucional; este derecho debe respetarse en toda actuación estatal cuando se vean comprometidos derechos de las personas. De ahí que el objetivo de la presente investigación fue demostrar que el procedimiento para sancionar las faltas leves en la Policía Nacional del Ecuador vulnera este derecho ya que incumple con las garantías de la oralidad y el derecho a ser oído de un servidor policial inculpado por este tipo de inconductas. De la investigación realizada se constató que en el Ecuador no existen establecidos parámetros o garantías mínimas que una autoridad pública debe garantizar en un procedimiento administrativo, como si existe en Colombia; sin embargo, la jurisprudencia ha referido que en procesos administrativos son aplicables las mismas garantías de un proceso jurisdiccional. 
De la encuesta realizada se pudo evidenciar que los profesionales del derecho que son policías en servicio activo y que cumplen funciones relacionadas a los procesos administrativos manifiestan que el procedimiento para sustanciar faltas leves no cumple con la oralidad y el derecho a ser oído, por lo tanto, vulnera el debido proceso, y como es obvio, con esta apreciación coincidieron los abogados en libre ejercicio de la profesión. Concomitante con ello, los servidores policiales expusieron que las resoluciones que se generan en el ámbito administrativo disciplinario policial son injustas debido a la vulneración de sus derechos constitucionales.

Ante esta situación, la solución sería que la Asamblea Nacional del Ecuador tramite la reforma del artículo 126 del Código Orgánico de las Entidades de Seguridad Ciudadana y Orden Público, incluyendo en este procedimiento las garantías de la oralidad y el derecho a ser oído, para que de esta manera, se garantice el debido proceso desde su esfera formal. Así también, la Corte Constitucional podría realizar un control abstracto de constitucionalidad, mediante la eliminación de esta evidente incompatibilidad normativa por motivo de fondo y a su vez unificar y adaptar el ordenamiento jurídico con la Constitución de la República (Asamblea Nacional del Ecuador, 2009). Para ello cualquier persona ostenta la legitimación activa para proponer esta acción.

De todo lo estudiado se concluye que el debido proceso en el ámbito administrativo disciplinario policial debe cumplir con las siguientes garantías mínimas: i) ser oído durante todo el proceso; ii) aplicación irrestricta de la oralidad en todas sus etapas; iii) ejercer contradicción de la prueba generada en su contra y solicitar e incorporar prueba a su favor; iv) notificación oportuna de todas las actuaciones de la administración; v) gozar de la presunción de inocencia; vi) participación activa desde el inicio hasta la culminación del proceso; vii) obligatoriedad a la autoridad con facultad sancionatoria de garantizar incluso de oficio el debido proceso y los derechos del servidor policial inculpado; viii) obtener una resolución basada en los principios constitucionales; ix) recurrir la decisión. 


\section{FINANCIAMIENTO}

No monetario.

\section{AGRADECIMIENTO}

Al personal de la Policía Nacional del Ecuador por permitir el desarrollo de la investigación.

\section{REFERENCIAS CONSULTADAS}

Asamblea Nacional Constituyente. (20 de Octubre de 2008). Constitución de la República del Ecuador [Constitution of the Republic of Ecuador]. Título IV Participación y Organización del Poder. Montecristi, Manabí, Ecuador: Registro Oficial No. 449.

Asamblea Nacional Constituyente. (20 de Octubre de 2008). Constitución de la República del Ecuador. [Constitution of the Republic of Ecuador]. Título II Derechos. Montecristi, Manabí, Ecuador: Registro Oficial No. 449.

Asamblea Nacional del Ecuador. (22 de Octubre de 2009). Ley Orgánica de Garantías Jurisdiccionales y Control Constitucional. [Organic Law of Jurisdictional Guarantees and Constitutional Control]. Título III. Quito, Pichincha, Ecuador: Registro Oficial Suplemento 52.

Asamblea Nacional del Ecuador. (7 de Julio de 2017). Código Orgánico Administrativo. [Organic Administrative Code] Recuperado de: https://n9.cl/y4bd9. Título I. Quito, Pichincha, Ecuador: Registro Oficial Suplemento 31. Obtenido de https://n9.cl/y4bd9

Asamblea Nacional del Ecuador. (21 de Junio de 2017). Código Orgánico de las Entidades de Seguridad Ciudadana y Orden Público. [Organic Code of Citizen Security and Public Order Entities] Recuperado de: https://n9.cl/j9vl. Libro I, Título III. Quito, Pichincha, Ecuador: Registro Oficial Suplemento 19. Obtenido de https://n9.cl/j9vl 
Asamblea Nacional del Ecuador. (21 de Junio de 2017). Código Orgánico de las Entidades de Seguridad Ciudadana y Orden Público. [Organic Code of Citizen Security and Public Order Entities] Recuperado de: https://n9.cl/j9vl. Título Preliminar. Quito, Pichincha, Ecuador: Registro Oficial Suplemento 19. Obtenido de https://n9.cl/j9vl

Burneo, R. E. (2010). Derecho Constitucional. [Constitutional right]. Quito, Pichincha, Ecuador: Corporación de Estudios y Publicaciones.

Calvinho, G. (22 de Diciembre de 2013). Blog Académico en Derecho Procesal. [Academic Blog in Procedural Law] Recuperado de: https://n9.cl/sk9xw. Obtenido de Distinción entre Derechos y Garantías: http://gustavocalvinho.blogspot.com/2013/12/distincion-entre-derechos-ygarantias.html

Cañarte , C., Erazo , J., Vázquez, J., \& Narváez , C. (2019). Derecho al proceso en el cometimiento de infracciones administrativas por propietarios de locales comerciales. [Right to process in the commission of administrative infractions by owners of commercial premises] Recuperado de: https://n9.cl/7mlc9. IUSTITIA SOCIALIS, 22. doi: http://dx.doi.org/10.35381/racji.v5i1.612

Corte Interamericana de Derechos Humanos. (2017). Cuadernillo de Jurisprudencia de la Corte Interamericana No. 12. [Jurisprudence Booklet of the Inter-American Court No. 12] Recuperado de: https://n9.cl/w1au. San José: Fundación Diálogo Jurisprudencial Iberoamericano. Obtenido de https://n9.cl/w1au

Guzmán, M. (2019). El principio constitucional de la tutela judicial efectiva vulnerado por la acción de nulidad de sentencias. [The constitutional principle of effective judicial protection violated by the action of nullity of sentences] Recuperado de: https://n9.cl/fOw8y. IUSTITIA SOCIALIS, 11. doi:DOI: 10.35381/racji.v4i7.366

Hernández, B. (2017). Sumario Administrativo y Debido Proceso. [Administrative Summary and Due Process] Recuperado de: https://n9.cl/uwqs. Quito: Corporación Editorial Nacional. Obtenido de https://n9.cl/uwqs

López, L., Narváez, C., Vázquez , J., \& Erazo, J. (2019). Derechos del debido proceso en los sumarios administrativos en la Ley Orgánica de Educación Intercultural. [Due process rights in administrative summaries in the Organic Law of Intercultural Education] Recuperado de: https://n9.cl/1qgs. IUSTITIA SOCIALIS, 21. doi: http://dx.doi.org/10.35381/racji.v5i1.633 
Organización de Estados Americanos. (22 de noviembre de 1969). Convención Americana sobre Derechos Humanos. [American Convention on Human Rights]. Capítulo II Derechos Civiles y Políticos. San José, San José, Costa Rica: Registro ONU: 08/27/79 No. 17955 Vol.S/N. Obtenido de https://n9.cl/zwq2x

Organización de Naciones Unidas. (16 de diciembre de 1966). Pacto Internacional de Derechos Civiles y Políticos. [International Covenant on Civil and Political Rights]. Parte III. Nueva York, Nueva York, Estados Unidos: Registro Oficial No. 101. Obtenido de https://n9.cl/sfmwn

Quiroz, D., \& Quiroz, C. (2016). La Oralidad en el Ámbito Jurídico en el Ecuador. [Orality in the Legal Field in Ecuador] Recuperado de: https://n9.cl/fjie. Revista Ámbito Jurídico, 11. Obtenido de https://n9.cl/fjie

Restrepo, J., \& Botero, J. (2018). El principio de oralidad en los Procesos Laborales colombo-venezolano en relación con la humanización y el derecho a la tutela judicial efectiva. [The principle of orality in the Colombian-Venezuelan Labor Processes in relation to humanization and the... Revista de la Facultad de $\begin{array}{lllll}\text { Derechos } y & \text { Ciencias Políticas - UPB, } & 14 .\end{array}$ doi:http://dx.doi.org/10.18566/rfdcp.v48n129.a12

Ruiz, A., Aguirre, P., \& Ávila, D. (2016). Desarrollo Jurisprudencial de la Primera Corte Constitucional. [Jurisprudential Development of the First Constitutional Court]. Quito: Centro de Estudios y Difusión del Derecho Constitucional. Obtenido de http://www.corteidh.or.cr/tablas/33423.pdf

Sentencia Apitz Barbera y otros ("Corte Primera de lo Contencioso Administrativo") vs. Venezuela. [Apitz Barbera et al. Judgment ("First Court of Administrative Litigation") vs. Venezuela] Recuperado de: https://n9.cl/wyus, Serie C No. 182, Párrafo 75 (Corte Interamericana de Derechos Humanos 05 de Agosto de 2008). Obtenido de https://www.corteidh.or.cr/docs/casos/articulos/seriec_182_esp.pdf

Sentencia Barbani Duarte y Otros Vs. Uruguay. Fondo Reparaciones y Costas. [Barbani Duarte and Others v. Uruguay Judgment. Fund Reparations and Costs] Recuperada de: https://n9.cl/21444, Serie C No. 234 (Corte Interamericana de Derechos Humanos 13 de Octubre de 2011). Obtenido de http://corteidh.or.cr/docs/casos/articulos/seriec_234_esp.pdf

Sentencia C-980/10. [Judgment C-980/10] Recuperada de: https://n9.cl/wf9v, Expediente D-8104 (Corte Constitucional de Colombia 1 de Diciembre de 2010). Obtenido de https://www.corteconstitucional.gov.co/relatoria/2010/c-980-10.htm 
Sentencia Flor Freire vs Ecuador. Excepción Preliminar, Fondo, Reparaciones y Costas. [Flor Freire vs. Ecuador judgment. Preliminary Objection, Merits, Reparations and Costs] Recuperado de: https://n9.cl/hyj6, Serie C No. 315 (Corte Interamericana de Derechos Humanos 31 de Agosto de 2016). Obtenido de https://www.corteidh.or.cr/docs/casos/articulos/seriec_315_esp.pdf

Sentencia No. 001-12-SEP-CC. [Judgment No. 001-12-SEP-CC] Recuperado de: https://n9.cl/apj96, 1619-10-EP (Corte Constitucional 5 de Enero de 2012). Obtenido de https://n9.cl/apj96

Sentencia No. 006-16-SCN-CC. [Judgment No. 006-16-SCN-CC] Recuperada de: https://n9.cl/inhc, 0013-15-CN (Corte Constitucional 31 de Agosto de 2016). Obtenido de https://n9.cl/inhc

Sentencia No. 018-09-SEP-CC. [Judgment No. 018-09-SEP-CC] Recuperado de: https://n9.cl/vhfd8, 0166-09-EP (Corte Constitucional para el período de Transición 23 de Julio de 2009). Obtenido de https://n9.cl/vhfd8

Sentencia No. 203-17-SEP-CC. [Judgment No. 203-17-SEP-CC] Recuperado de: https://n9.cl/1apz, 1027-11-EP (Corte Constitucional 30 de Junio de 2017). Obtenido de https://n9.cl/1apz

Sentencia Rosadio Villavicencio Vs. Perú. Excepciones Preliminares, Fondo, Reparaciones y Costas. [Rosadio Villavicencio v. Peru Judgment. Preliminary Exceptions, Merits, Reparations and Costs] Recuperada de: https://n9.cl/iehe, Serie C No. 388 (Corte Interamericana de Derechos Humanos 14 de Octubre de 2019). Obtenido https://www.corteidh.or.cr/docs/casos/articulos/seriec_388_esp.pdf

Sentencia T-001/19. [Judgment T-001/19] Recuperada de: https://n9.cl/k7qv, Expediente T-6.577.482 (Corte Constitucional de Colombia 14 de Enero de 2019). Obtenido de https://www.corteconstitucional.gov.co/relatoria/2019/t-001-19.htm

Villadiego, C. (2010). La oralidad en la justicia civil como elemento del debido proceso: un enfoque de derechos humanos. [Orality in civil justice as an element of due process: a human rights approach] Recuperado de: https://n9.cl/2ha8. Civilizar Ciencias Sociales y Humanas, 15-25. Obtenido de http://www.scielo.org.co/pdf/ccso/v10n18/v10n18a03.pdf 
Iustitia Socialis. Revista Arbitrada de Ciencias Jurídicas.

Año V. Vol. V. №2. Edición Especial. 2020-II

Hecho el depósito de Ley: FA2016000064

ISSN: 2542-3371

FUNDACIÓN KOINONIA (F.K). Santa Ana de Coro, Venezuela

Richard Fernando Cuenca-Correa; Cecilia Ivonne Narváez-Zurita; Juan Carlos Erazo-Álvarez; Diego Fernando Trelles-Vicuña

(C2020 por los autores. Este artículo es de acceso abierto y distribuido según los términos y condiciones de la licencia Creative Commons Atribución-NoComercial-Compartirlgual 4.0 Internacional (CC BY-NC-SA 4.0) (https://creativecommons.org/licenses/by-nc-sa/4.0/). 